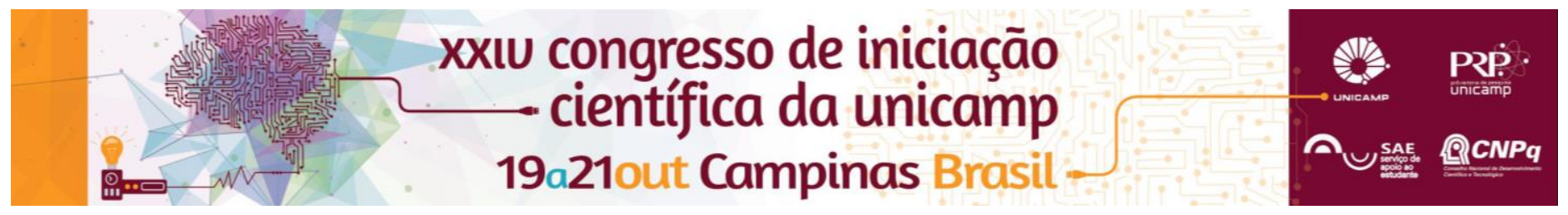

\title{
Prevalência de hipocalcemia neonatal e infecções de repetição/imunodeficiências em indivíduos investigados por suspeita da Síndrome de Deleção 22q11.2.
}

\author{
Amanda Comegna dos Santos*, Vera Lúcia Gil-da-Silva-Lopes, Roberta Mazzariol Volpe Aquino, Amanda \\ Ferreira Mora, llária Cristina Sgardioli.
}

\begin{abstract}
Resumo
A Síndrome de Deleção 22q11.2 é a mais comum microdeleção cromossômica da espécie humana, com grande variabilidade fenotípica. Pode estar associada com hipocalcemia neonatal idiopática e imunodeficiências. Apesar dessas duas manifestações serem importantes na SDel 22q11.2, sua heterogeneidade clínica pode atrasar o diagnóstico, comprometendo o manejo global e o aconselhamento genético. O objetivo deste estudo é contribuir para o diagnóstico da SDel 22q11.2 por meio da identificação da prevalência de hipocalcemia neonatal e infecções recorrentes/imunodeficiências em casos com suspeita de SDel 22q11.2. Foram utilizados dados de pacientes coletados na CranFlow- BDDEL22q11.2 (Brazilian database on 22q11.2 deletion syndrome), e comparados os resultados dos casos confirmados e os negativos para esta microdeleção. Quanto às variáveis estudadas, percebeu-se baixas frequências de casos com relato de hipocalcemia ou imunodeficiências, não sendo possível considerar estas variáveis como sinais cardinais que indicassem investigação de SDel 22q11.2. Já em relação a história clínica de infecções, análise estatística demonstrou diferença significativa desta variável quando relacionada a voz anasalada, refluxo gastroesofágico e defeitos cardíacos específicos, sendo essa ssociação relevante na medida em que pode servir de alerta para a necessidade de investigação da SDel 22q11.2.
\end{abstract}

\section{Palavras-chave:}

Deleção 22q11.2, imunodeficiência, hipocalcemia neonatal idiopática.

\section{Introdução}

A Síndrome de Deleção 22q11.2 (SDel 22q11.2) é a mais comum microdeleção cromossômica da espécie humana, com grande variabilidade fenotípica [1]. Sua associação com hipocalcemia neonatal idiopática devese a hipoplasia ou aplasia da paratireoide, com falha na produção do PTH [2]. Imunodeficiências na SDel22q11.2 ocorrem por aplasia ou hipoplasia do timo com problemas no processo de produção de linfócitos $T$ [3], com gravidade e frequência variáveis. A heterogeneidade clínica dessas manifestações pode atrasar o diagnóstico nestes pacientes. Em 2013, foram publicados por este grupo de pesquisa critérios clínicos para a suspeição de SDel 22q11.2, os quais embasaram a construção de módulo específico para apoio diagnóstico na aplicação CranFlow (CranFlow- BDDEL22q11.2 - Brazilian database on 22q11.2 deletion syndrome) que registra casos suspeitos e a soma os sinais clínicos de maneira evolutiva. O objetivo deste estudo é contribuir para o diagnóstico da SDel 22q11.2 por meio da identificação da prevalência de hipocalcemia neonatal e infecções recorrentes/imunodeficiências em casos com suspeita de SDel 22q11.2.

\section{Resultados e Discussão}

Foram consultados todos os casos registrados na CranFlow ${ }^{\circledR}$-BDDEL22q11.2 até $16 / 03 / 2016$, totalizando 330 casos. Destes, 301 foram testados para a SDel 22q11.2 pelos métodos de FISH (Fluorescent in situ Hybridization) e/ou MLPA (Multiplex ligation-dependent probe amplification). Os casos com história de hipocalcemia neonatal, hipocalcemia pós-natal, infecções recorrentes e imunodeficiências foram incluídos na análise final dos dados utilizando o programa Epi-Info 3.5.1, versão 17.0. Em relação à análise final dos dados, percebe-se baixas frequências de casos com relato de hipocalcemia ou imunodeficiências. Assim, não foi possível considerar estas variáveis como sinais cardinais que indicassem investigação de SDel 22q11.2. Já em relação a história clínica de infecções, análise estatística demonstrou diferença significativa desta variável quando relacionada a voz anasalada $(p=0,010)$, refluxo gastro-esofágico (RGE) $(p=0,026)$ defeitos cardíacos específicos (dupla saída de ventrículo direito; transposição de grandes artérias; comunicação interatrial e/ou forame oval pérvio; outros defeitos de septo interventricular além de defeito subarterial/subpulmonar, defeito acompanhado de atresia pulmonar, mal alinhamento posterior ou estenose pulmonar) $(p=0,035)$.

\section{Conclusões}

Os resultados evidenciaram que infecções na infância associadas às cardiopatias citadas, voz anasalada ou RGE podem sugerir o diagnóstico de SDel 22q11.2. Essa associação é relevante na medida em que pode servir de alerta para a necessidade de investigação de SDel 22q11.2, contribuindo para detecção precoce na população.

Apoio: Fapesp e CNPq

\section{Agradecimentos}

[1] YamagishiH. The 22q11.2 deletion syndrome. Keio J Med. 2002;51 (2):77-88.

[2] NusseySS, Whitehead SA. Endocrinology: An Integrated Approach, BIOS Scientific Publishers; 2001.

[3] SullivanKE, JawadAF, RandallP, DriscollDA, Emanuel BS, McDonaldMcGinnDM, ZackaiEH. Lack of correlation between impaired $\mathrm{T}$ cell production, immunodeficiency, and other phenotypic features in chromosome 22q11.2deletion syndromes. ClinImmunopathol. 1998;86:141-14. 